\title{
Análise semiótica do poema Vulgívaga de Manuel Bandeira
}

\author{
José Ferreira de LUCENA JÚNIOR \\ (FFLCH-USP)
}

\begin{abstract}
RESUMO: Neste trabalho é realizada uma análise semiótica do poema Vulgívaga do poeta modernista brasileiro Manuel Bandeira. Para tal utiliza-se da teoria da semiótica das paixões de Greimas e de estudos atualizados sobre o assunto. Com essa análise pretende-se encontrar uma justificativa para a preferência sexual do eu lírico do poema.
\end{abstract}

PALAVRAS-CHAVE: semiótica; poesia; erotismo; discurso.

\begin{abstract}
The object of this work is to present a semiotic analysis of Manuel Bandeira's poem "Vulgivaga". For such we utilized the semiotic theory of the passions and other studies on this matter. Through this analysis we intend to find out a justification for the sexual preference of the ethos in the poem.
\end{abstract}

KEYWORDS: semiotics; poetry; erotism; discourse. 


\section{Introdução}

Manuel Bandeira é considerado, entre os grandes representantes da poesia modernista brasileira, aquele que tem a obra com os temas mais diferentes. Há uma variação que vai do nacionalismo até a morte, passando por recordações da infância, amores e fatos cotidianos. Um desses temas diz respeito ao erotismo presente em alguns de seus poemas. Assim como o total de sua obra, o tema do erotismo aparece de variadas maneiras.

Este trabalho pretende realizar uma análise semiótica de um desses poemas de cunho erótico: Vulgívaga. A análise se dará de acordo com a teoria da semiótica das paixões desenvolvida por A. J. Greimas contando com o apoio de estudos atualizados sobre o assunto.

Como a semiótica estuda o como se faz para se dizer o que se diz, ou seja, a significação, pouco interessa aqui uma interpretação do poema. Em outras palavras, com a semiótica, deseja-se saber como se dá a construção do sentido (o que se diz). O sentido, por sua vez, é formado no conteúdo, nesse caso, um texto escrito. Portanto, é o sentido construído nos textos o objeto privilegiado de uma semiótica geral que deseja dar conta do que Saussure denominou significado e que Hjelmslev precisou como plano do conteúdo. A significação se realiza por meio do discurso. O discurso é o lugar de produção das visões de mundo e de pontos de vista. É nele, portanto, que se formam os sistemas e os valores de uma cultura. Assim, há uma construção deste em relação a outros discursos.

A semiótica greimasiana utiliza-se do percurso gerativo do sentido para realizar sua exploração de um texto. O quadrado semiótico é ferramenta fundamental do percurso para a análise semiótica. Uma descrição de cada etapa do percurso se dará e se mostrará sua aplicação sobre o poema escolhido.

Sabendo-se que a poesia é gênero em que as conotações são predominantes e ainda levando-se em consideração uma teoria sobre isotopias para esse tipo de texto (ver Rastier in Greimas, 1975, pp. 96-125) esta análise se realizará sobre o tom denotativo do poema.

Interessa, neste trabalho, o discurso erótico existente no poema. A análise versará sobre uma visão de mundo a respeito do assunto. Nela, o eu lírico do poema, a própria vulgívaga, valoriza o erotismo de modo diferente daquele considerado normal pela sociedade. Há uma euforização do sexo violento. A análise do discurso erótico é realizada no final tentando justificar essa visão de mundo do eu lírico.

Com a análise, revela-se a face do poeta que respeita os variados tipos de preferências sexuais expondo-os na forma de poema para apreciação e avaliação do mundo. Contudo, considerando-se quem seja o poeta, não se deve avalizar o poema apenas pelo seu conteúdo erótico. Outras leituras possíveis (caráter conotativo do poema) podem se realizar utilizando-se do mesmo percurso aqui trabalhado. Um exemplo é aquele em que a figura da vulgívaga representa o homem no mundo e suas relações com os fatos de seu entorno. 


\section{0 percurso gerativo do sentido}

O percurso gerativo do sentido é um modelo teórico que descreve a significação. Ou seja, como se dá a produção do sentido do texto, num processo que vai do mais simples e abstrato ao mais complexo e concreto. $\mathrm{O}$ percurso gerativo do sentido é composto de três etapas ou níveis:

Nível fundamental: é o patamar mais simples e abstrato em que a significação se apresenta como uma oposição semântica.

Nível narrativo: neste patamar organiza-se a narrativa do ponto de vista de um sujeito.

Nível discursivo: é o patamar mais complexo e concreto e onde a organização narrativa converte-se em discurso por meio dos procedimentos de temporalização, espacialização, actorialização, tematização e figurativização, que completam o enriquecimento e a concretização semântica (Barros in Fiorin, 2003, p. 188).

\section{Nível fundamental}

Deve-se considerar as categorias semântica e fórica que estão na base da construção de um texto. A categoria fórica é projetada sobre a semântica sendo que a euforia caracteriza um valor positivo e a disforia um valor negativo. Portanto, a projeção das categorias fóricas dá-se segundo o ponto de vista de um sujeito. A escolha da categoria semântica deve ser adequada de modo a permitir uma sistematização dos valores (relação entre dois termos contrários).

Para o poema Vulgívaga a relação semântica é integração vs. transgressão e a projeção fórica dá-se como eufórica para a transgressão e disfórica para a integração.

O quadrado semiótico realiza a sintaxe das relações sistematizadas. Pode-se representá-las e visualizá-las, traduzindo suas relações em oposições de contradição, contrariedade e complementaridade. Integração e transgressão mantêm entre si relação de oposição sendo declarados termos contrários.

O quadrado semiótico para as duas categorias mostrasse assim:

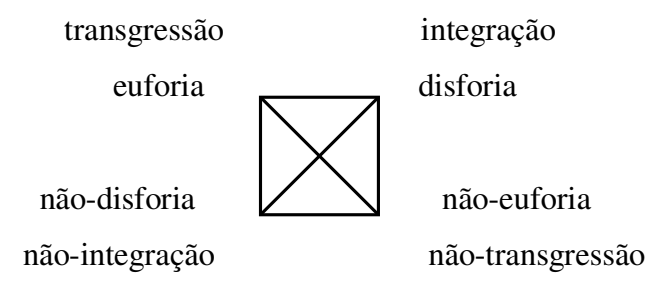

No nível fundamental os valores de transgressão e integração são gerados por meio da categoria transgressão vs. integração, aplicada sobre uma norma social que rege os chamados bons costumes em relação ao sexo, diz-se que a categoria semântica é da dimensão do inteligível. A projeção da categoria fórica, da dimensão do sensível, determina um estado de alma para o sujeito narrativo que também pode ser projetado no 
quadrado semiótico. Há um efeito de relaxamento para esse sujeito com a euforia. Relaxado, o sujeito investe na continuidade desse estado. A disforia leva ao efeito de retenção e o sujeito vai investir na parada desse estado para voltar ao estado de relaxamento. $\mathrm{O}$ quadrado semiótico que se origina a partir desses termos ditos tensivos é o seguinte:

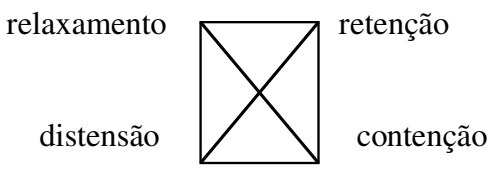

De acordo com Tatit (Tatit em Fiorin, 2002: 200), há um percurso das categorias tensivas que leva à definição de uma categoria fórica da seguinte maneira:

Relaxamento $\Rightarrow$ contenção $\Rightarrow$ retenção gera a disforia e;

Retenção $\Rightarrow$ distensão $\Rightarrow$ relaxamento, gera a euforia.

Foria e tensividade vão incidir sobre o vir a ser do sujeito narrativo em relação aos objetos de valor. O investimento nesse vir a ser faz com que o indivíduo queira permanecer num estado (disfórico) ou trabalhe de alguma maneira para livrar-se do estado não desejado (disfórico). Fala-se então em parada e continuação do estado de relaxamento. O quadrado semiótico representativo da parada e continuação de acordo com o mesmo autor (Tatit em Fiorin, 2002: 201) fica assim:

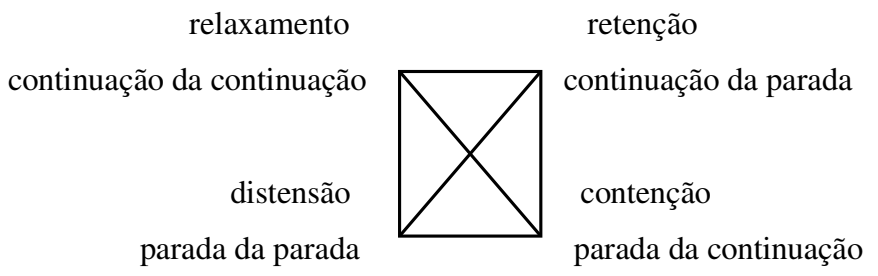

\section{Nível narrativo}

Com a determinação e sensibilização dos valores no nível fundamental estes devem ser convertidos em objetos de valor para que se saiba como se darão as relações juntivas do sujeito narrativo com o mesmo. As relações juntivas, também chamadas de enunciados de ser, mostram a relação ideal para o sujeito narrativo. O sujeito sempre deseja estar em conjunção com o objeto de valor, no entanto, não é verdade que isso sempre aconteça. No poema, o sujeito narrativo quer estar em conjunção com o gozo físico fornecido somente por um "mundo sexual" não considerado adequado pelos padrões sociais. 
O sujeito narrativo, a vulgívaga do poema, quer estar em conjunção com a transgressão. Isso acontece quando se coloca nas mãos dos tipos que a satisfazem. Deste modo, o sujeito está em estado relaxado. Este estado ocorre quando se dá a continuação da continuação da conjunção com os valores eufóricos. O vir a ser do sujeito narrativo forma-se de modo a manter a conjunção com o valor da transgressão dados nas figuras do amante bêbado, do marido tísico, do que fere toda a lira, do que lhe agride fisicamente ou de algum canalha.

Porém, quando se coloca nas mãos de profissionais liberais, artistas, ingênuos etc. não entra em conjunção com o objeto de valor. Não há o gozo físico, mas, insatisfação.

Há de se considerar que o sujeito narrativo é o sujeito do ser e que este deverá manter uma relação com um sujeito do fazer para obter ou não o objeto de valor. Formam-se assim, as paixões complexas resultantes das relações passionais entre os dois sujeitos. O dever-ser da relação entre o sujeito do ser e o objeto de valor e também o dever-fazer do sujeito do fazer definirão essas paixões. Em uma relação onde o sujeito do ser é colocado em conjunção com o objeto de valor pelo sujeito do fazer esse contrato é cumprido. Usando o trabalho de Pietroforte, 2003, a representação no quadrado semiótico fica da seguinte maneira:

\section{dever-ser}

sujeito do ser $\cap$ sujeito do fazer

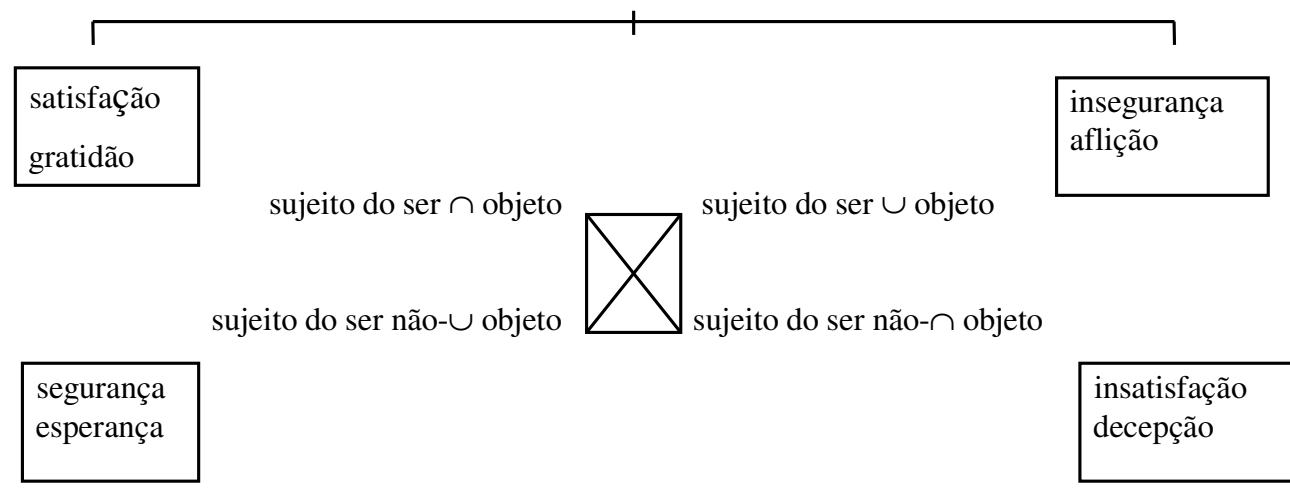

No poema, o sujeito do ser estará em conjunção com o objeto de valor quando o sujeito do fazer for aquele que fere toda a lira ou aquele que a agride fisicamente. Assim, o sujeito do fazer quando fere a lira ou quando agride ao sujeito narrativo faz com que este entre em conjunção com o objeto de valor gozo físico e gera a paixão da satisfação no sujeito do ser.

Para se entender melhor o quadrado e as relações pode-se supor outras relações não presentes no poema. Deste modo, se o sujeito do fazer, o que a agride fisicamente, 
por exemplo, não bater nela, vai-se gerar uma decepção na vulgívaga já que ela está esperando pela pancada. Há aqui uma não conjunção do sujeito do ser com o objeto de valor.

Os canalhas, aqueles que podem usar da navalha, vão colocar o sujeito do ser em estado de insegurança e/ou aflição, pois o uso da navalha não dá o gozo físico, mas sim, o sofrimento físico. Ocorre a disjunção do sujeito narrativo com o objeto de valor. Se o sujeito narrativo souber que a navalha não será usada provoca-se uma paixão de segurança e/ou esperança de que possa adquirir o objeto de valor gozo físico.

Se há uma conjunção do sujeito do ser com o sujeito do fazer pode-se inferir que há também uma relação de disjunção, outra de não-conjunção e finalmente uma de não disjunção com as articulações do dever-não-ser, não-dever-ser e não-dever-não-ser respectivamente.

Formam-se quatro relações que também podem ser colocadas em um quadrado semiótico para sua melhor análise. No quadrado semiótico a seguir o sujeito 1 é o sujeito do ser e o sujeito 2 é o sujeito do fazer.

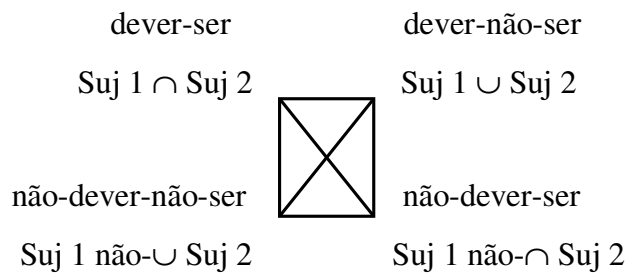

Quando o sujeito narrativo, a vulgívaga, refere-se, no poema, ao médico, ao poeta, velhos, fervidos, artistas e tímidos, enfim aos sonhadores e ingênuos, está se referindo àqueles que não conseguem colocá-la em conjunção com o objeto de valor gozo físico já que têm uma visão de mundo diferente. Os sujeitos, nesse caso, encontram-se num estado de não conjunção em que não existe uma confiança plena entre si. Gera-se um não-dever-ser. Para este caso:

não dever-ser

sujeito do ser não- $\cap$ sujeito do fazer

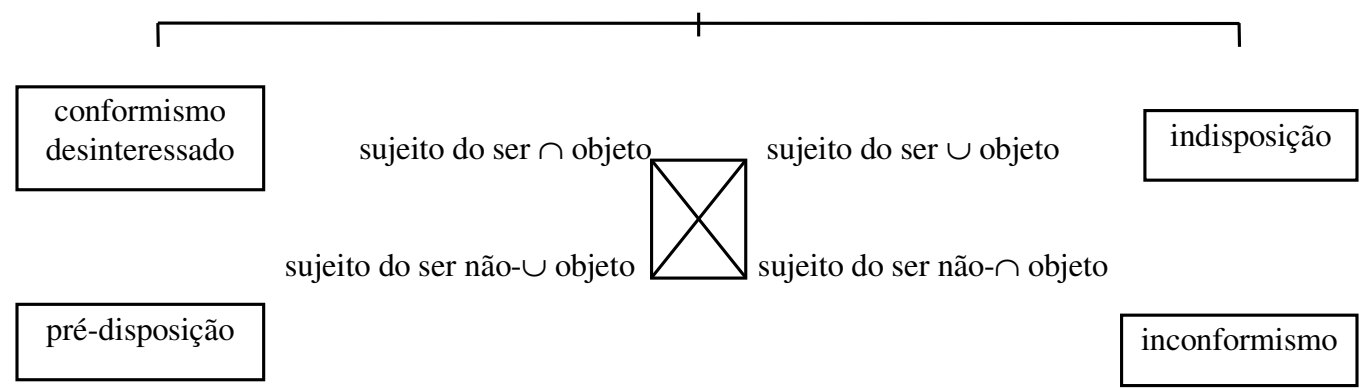


A não conjunção entre os sujeitos gera paixões com um tom de indiferença.

O conformismo desinteressado é gerado pelo poeta, pelo médico e outro pois esses podem colocar a vulgívaga em conjunção com o objeto de valor mas não há uma confiança no sujeito do fazer para realizar essa conjunção satisfatoriamente.

$\mathrm{O}$ inconformismo aparece com os sonhadores e ingênuos. Quando diz $\mathrm{Meu}$ claro ventre nunca foi / De sonhadores e ingênuos! quer significar que esses não serão capazes de colocarem-na em conjunção com o gozo físico.

A indisposição revela-se para com os canalhas pois estes a farão estar em disjunção com o objeto de valor ao usar da navalha. Deve-se pensar, neste caso, em uma interpretação para o caso dos canalhas em que o sofrimento causado pela navalha é certo. Não deve haver uma confusão com as relações em que os sujeitos estão em conjunção.

Uma pré-disposição é gerada se houver uma não disjunção com o objeto de valor, é o que acontece com os velhos, fervidos, artistas e tímidos pois o sujeito do ser os satisfaz em suas necessidades mas também faz com que os caçoe e depene fornecendo um outro tipo de satisfação para a vulgívaga.

Realizada a perfórmance deve-se avaliar seu sucesso com o percurso do julgamento. No percurso há sistematização do saber que pode ser articulada em um quadrado semiótico montado da seguinte maneira:

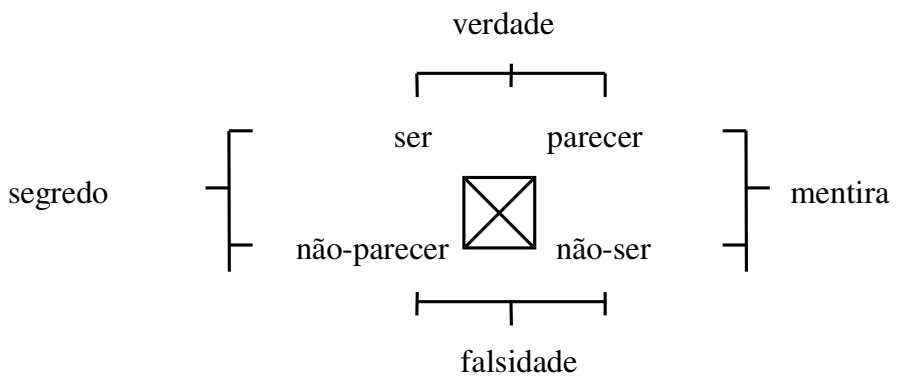

A categoria ser vs. parecer é veridictória e adequada para estabelecer o dizer verdadeiro a respeito da perfórmance. A articulação das categorias integração vs. transgressão está aplicada sobre a concepção do amor sendo que há a euforização da transgressão na concepção da vulgívaga ao preferir o gozo físico a um outro gozo fornecido por "clientes" cuja concepção do amor é mais aceita socialmente mas disforizada pelo sujeito narrativo.

A perfórmance se realiza quando do ato sexual e seu julgamento será realizado de acordo com quem estiver com o sujeito narrativo. A perfórmance aqui depende do destinador (cada pessoa com quem a vulgívaga tem relações sexuais) já que tem como papel colocar o sujeito (a vulgívaga) em conjunção com o objeto de valor gozo físico. $\mathrm{O}$ 
julgamento se dará de acordo com o cumprimento de um contrato entre os actantes. De acordo com Barros:

"O contrato de veridicção determina as condições para o discurso ser considerado verdadeiro, falso, mentiroso ou secreto, ou seja, estabelece os parâmetros, a partir dos quais o enunciatário pode reconhecer as marcas da veridicção que como um dispositivo veridictório, permeiam o discurso." (Barros, 2002: 94).

Ao relacionar-se com o que fere a lira ou com o que a agride, a vulgívaga entra em uma conjunção com o objeto de valor gozo físico, então o sujeito narrativo é e parece satisfeito sexualmente provocando o efeito de verdade. A avaliação da perfórmance diz que houve um sucesso.

Nas relações com o poeta, o médico, velhos, fervidos, artistas e tímidos (destinatários julgados), a vulgívaga parece obter uma satisfação sexual, pois lhes dá o engulho, o que os esfrie, a coquetterie e o orgulho, ou seja, faz com que estes pensem ser plenamente capazes de lhe fornecer uma satisfação sexual. Portanto, a vulgívaga parece obter o gozo físico mas não é satisfeita e a perfórmance é julgada como uma mentira.

Os canalhas podem levar a dois resultados: o primeiro é aquele que fica na imaginação da vulgívaga pois os canalhas podem satisfazê-la em relação ao gozo físico mas não os procura por temor da navalha. Assim, o destinador julgador é mas não parece satisfeito e a satisfação permanece em segredo. $\mathrm{O}$ segundo é aquele em que a perfórmance seria julgada como falsa se realmente se entregasse aos canalhas e estes usassem da navalha. Então não há o gozo físico mas o sofrimento porque o destinatário manipulado não é e não parece satisfeito sexualmente.

Completa-se, com isto, o esquema narrativo formado pela articulação dos percursos de manipulação, ação e julgamento. Após a descrição do esquema narrativo as paixões serão concretizadas na forma de figuras no nível discursivo.

\section{Nível discursivo}

É no nível discursivo que as paixões são especificadas e concretizadas e o primeiro passo é fazer com que os arranjos modais do nível narrativo sejam espacializados, temporalizados e actorializados.

Para o poema Vulgívaga há uma narradora que fala na primeira pessoa (não posso crer, o meu amante, o meu marido, dou tudo etc.). Caracteriza-se assim uma enunciação do tipo enunciativa onde a relação pessoal é do tipo EU-TU, os tempos verbais marcam o tempo do AGORA e o espaço é o AQUI. Ocorre a coincidência do sujeito narrativo com o enunciador que está marcado na pessoa do EU. Essa coincidência reforça uma característica da enunciação enunciativa que é a de ser subjetiva. Ao coincidir com o Eu, o sujeito narrativo será aquele que vai entender e sentir a paixão no nível fundamental. O efeito derivado é que a subjetividade ganha força. Na relação enunciação-enunciado (relação da enunciação com o enunciado) uma aproximação é produzida.

Deste modo, para o poema trabalhado, a sintaxe discursiva configura-se de acordo com o seguinte quadro: 


\begin{tabular}{|l|l|l|l|l|c|}
\hline enunciação & pessoa & tempo & espaço & $\begin{array}{c}\text { efeito de } \\
\text { sentido }\end{array}$ & $\begin{array}{c}\text { relação enunciação- } \\
\text { enunciado }\end{array}$ \\
\hline enunciativa & eu-tu & agora & aqui & subjetivação & aproximação \\
\hline
\end{tabular}

Procura-se recobrir essa sintaxe com uma semântica discursiva para que a concretização das paixões seja efetivada. Deve-se prever os percursos figurativos e temáticos do discurso. O tema recorrente em Vulgívaga é o da sexualidade. Esse tema, de caráter geral, poderia ser discutido sob vários pontos de vista e a paixão gerada refletiria estados de alma. No entanto, o poema tem um percurso figurativo dominante e que, portanto, reflete apenas o estado de uma alma, a da vulgívaga. Com esse estatuto a paixão geral da sexualidade terá desdobramentos que estão figurativizados no texto.

A descrição do universo passional de uma cultura, não importando o modo de expressão, é realizada por meio das palavras. Deste modo, a lexicalização das paixões vai definir como uma cultura as define em seus discursos. No poema, sabe-se que o tema recorrente é a sexualidade ou sexo e os léxicos usados e referenciais são amor, gozo e mais indiretamente, vulgívaga (prostituta). Para uma definição de sexo recorre-se ao dicionário. No dicionário Houaiss, sexo é definido assim:

\section{Sexo}

1. no Homem, conformação física, orgânica celular, particular que permite distinguir o homem e a mulher, atribuindo-lhes um papel específico na reprodução;

2. nos animais, conjunto das características corporais que diferenciam, numa espécie, os machos e as fêmeas e que lhes permitem reproduzir-se;

3. nos vegetais, conjunto de características que distinguem os órgãos reprodutores femininos e masculinos;

4. conjunto das pessoas que pertencem ao mesmo sexo

5. sensualidade, lubricidade, volúpia, sexualidade.

De acordo com as definições percebe-se que sexo tem um valor utilitário, quando se refere à reprodução, diferenciação entre macho e fêmea ou órgãos reprodutores, ou valor existencial quando tem um fim em si mesmo. No primeiro caso, o da valorização utilitária, há uma figurativização de um saber-fazer (distinção entre machos e fêmeas) ou poder-fazer (finalidade reprodutiva). Na definição 5 do dicionário em que sexo é sensualidade, volúpia e lubricidade a figurativização é de uma paixão. $\mathrm{O}$ sexo será desejado por si mesmo e o sujeito narrativo estará apaixonado (estado de alma).

Fontanille e Zilberberg apresentam um modelo que pode explicar as relações tensivas entre as valorizações utilitária e existencial de sexo e sexualidade. No modelo a valorização utilitária do sexo é da ordem da extensidade, devido ao fato de ser aplicado às coisas do mundo e a existencial é da ordem da intensidade pois vale por si mesmo e 
não por ou para algo. Usando-se os termos tônico e átono para que sejam projetados sobre os eixos da intensidade e extensidade, acaba-se gerando um gráfico como o que segue:

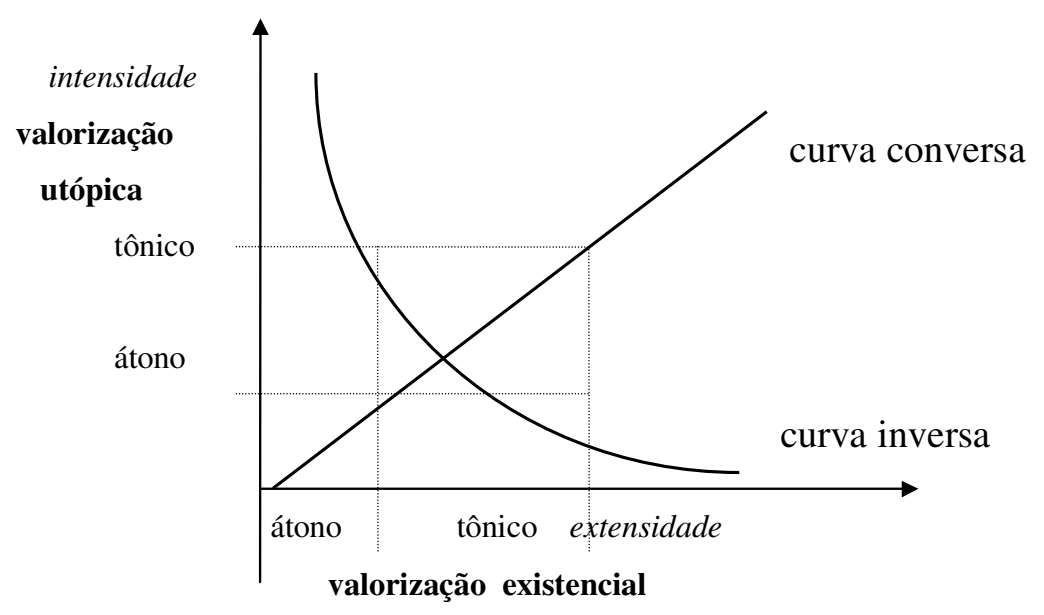

Geram-se duas curvas: uma curva conversa onde o aumento da valorização utilitária também provoca o aumento da valorização prática ou existencial; uma curva inversa, em que as relações se dão ao contrário da primeira. Por exemplo, a um aumento da valorização utilitária segue-se uma diminuição da valorização existencial.

A análise da curva inversa vai mostrar duas maneiras inversas de se valorizar o sexo e que sobre elas se projetam os valores eufóricos ou disfóricos em relação à tonicidade. Considerando-se o discurso do dicionário se a tônica estiver na valorização utilitária, e o sexo é definido como natureza, ocorre uma euforização desses conteúdos relacionados com a reprodução e distinção natural entre macho e fêmea. Se a tônica cair sobre a valorização existencial há uma definição cultural de sexo e os termos volúpia e lubricidade geram uma disforização já que segundo o mesmo dicionário esses termos representam:

lubricidade

2. propensão para a luxúria, sensualidade exagerada, excitação, lascívia.

volúpia

2. grande prazer sexual, luxúria.

Luxúria, por sua vez:

luxúria

2. segundo a doutrina cristã, um dos sete pecados capitais; 
3. comportamento desregrado em relação aos prazeres do sexo, lascívia, concupiscência.

Deve-se perceber que há uma visão de mundo ditada pelas definições do discurso do dicionário e que são reveladas pelas relações tensivas na curva. No poema analisado o discurso é tônico na valorização existencial e átono na valorização utilitária do sexo o que implica em se descobrir o por quê dessa valorização existencial, como se dá a projeção fórica de acordo com essa valorização e como trata os outros discursos sobre sexo.

O por quê diz respeito ao tipo de sexo que a vulgívaga prefere. De acordo com o texto tem-se que é do tipo sadomasoquista já que obtêm o gozo físico dos que ferem a lira ou daqueles que a agridem fisicamente (relação masoquista). Com essas afirmações fica fortemente marcada a valorização existencial do sexo. Pode-se depreender que o sexo obtido do artista, poeta, médico e outros não é do tipo sadomasoquista, mas de um tipo que não é objeto de valor para a vulgívaga.

A projeção fórica fará com que a atitude transgressora de sentir prazer com uma agressão física seja considerada eufórica e a integração, representada pelo sexo que se pode chamar de "normal" fica disforizada. De acordo com a visão de mundo da vulgívaga o seu objeto de desejo está na transgressão de só conceber do amor (sexo) o gozo físico e nunca um "espiritual" ou com objetivo de reprodução etc.

A atitude do sujeito narrativo, em relação aos demais discursos, dá-se na relação identidade vs. alteridade onde seu discurso representa uma oposição a posturas diferentes gerando uma intolerância para com os demais pois são incompatíveis com sua visão de mundo.. A afirmação dessa intolerância dá-se com o refrão:

\author{
Não posso crer que se conceba \\ Do amor senão o gozo físico! \\ O meu amante morreu bêbado, \\ E meu marido morreu tísico!
}

Especificam-se, assim, os campos passionais e suas modalizações com a definição da paixão da luxúria já que o objeto do desejo é a satisfação sexual física.

\title{
REFERÊNCIAS BIBLIOGRÁFICAS
}

BARROS, Diana L. P. (2002) Teoria do discurso: fundamentos semióticos. São Paulo: Humanitas/FFLCH/USP.

FIORIN, J. L. (org.) (2002). Introdução à lingüística. São Paulo: Contexto.

FONTANILlE, J. \& ZILBERBERG, C. (1998). Tensão e significação. São Paulo: Humanitas.

GREIMAS, A. J. (org.) (1975). Ensaios de semiótica poética. São Paulo: Cultrix; Ed. da Universidade de São Paulo. 
PIETROFORTE, A. V. S. (xerox, s/d). Entre o erótico e o pornográfico - Análise de uma fotografia veiculada pela internet.

PIETROFORTE, A. V. S. (2003). Ação e paixão no esquema narrativo. In: $9^{\circ}$. Caderno de discussão do Centro de Pesquisas Sociossemiótica. Editora CPS, pp. 361-376. 


\section{VULGÍVAGA}

Não posso crer que se conceba

Do amor senão o gozo físico!

O meu amante morreu bêbado,

E meu marido morreu tísico!

Não sei entre que astutos dedos

Deixei a rosa da inocência.

Antes da minha pubescência

Sabia todos os segredos...

Fui de um... Fui de outro... Este era médico...

Um, poeta... Outro, nem sei mais!

Tive em meu leito enciclopédico

Todas as artes liberais.

Aos velhos dou meu engulho.

Aos fervidos, o que os esfrie.

A artistas, a coquetterie

Que inspira... E aos tímidos - o orgulho.

Estes, caçôo-os e depeno-os:

A canga fez-se para o boi...

Meu claro ventre nunca foi

De sonhadores e ingênuos!

E todavia se o primeiro

Que encontro, fere toda a lira,

Amanso. Tudo se me tira.

Dou tudo. E mesmo... dou dinheiro...

Se bate, então como estremeço!

Oh, a volúpia da pancada!

Dar-me entre lágrimas, quebrada

Do seu colérico arremesso...

E o cio atroz se me não leva

A valhacoutos de canalhas,

É porque temo pela treva

$\mathrm{O}$ fio fino das navalhas...

Não posso crer que se conceba 
Do amor senão o gozo físico!

$\mathrm{O}$ meu amante morreu bêbado,

E meu marido morreu tísico!

\section{Como citar este artigo:}

LUCENA JÚNIOR, José Ferreira de. Análise semiótica do poema "Vulgívaga" de Manuel Bandeira. Estudos Semióticos, Número 2, São Paulo, 2006. Disponível em <www.fflch.usp.br/dl/semiotica/es>. Acesso em "dia/mês/ano". 